\title{
Enfoque subalterno e historia latinoamericana: nación, subalternidad y escritura de la historia en el debate Mallon-Beverley
}

\author{
Guillermo Bustos \\ Universidad Andina Simón Bolívar, Quito \\ gbustos@uasb.edu.ec
}

Fecha de recepción: 1 de agosto de 2002

Fecha de aceptación: 1 de octubre de 2002

\section{Resumen}

Este ensayo analiza un caso que ilustra la forma en que el enfoque subalternista, desarrollado originalmente por el Grupo de Estudios Subalternos de la India, fue adoptado por parte de los estudiosos de Latinoamérica, en especial el Grupo de Estudios Subalternos Latinoamericano, a comienzos de los años noventa. Se trata del debate sobre la relevancia, alcances y problemáticas que se desprenden de la aplicación de esta perspectiva en la escritura de la historia, adelantado por la historiadora Florencia Mallon y el crítico cultural John Beverley. Se evalúan los argumentos de ambas partes, teniendo en cuenta el hecho fundamental de que el debate se ha desarrollado en el marco de la academia norteamericana, lo que dificulta la participación de académicos latinoamericanos en igualdad de condiciones. Se concluye con una serie de reflexiones sobre cuatro temas generales, con el fin de evaluar los problemas y desafíos que surgen de los asuntos tratados: el acceso al corpus subalternista, la crítica al nacionalismo en la operación historiográfica, la acción del subalterno y el acecho del positivismo.

Palabras clave: ENFOQUE SUBALTERNO, GRUPO DE ESTUDIOS SUBALTERNOS DE LA INDIA, GRUPO DE ESTUDIOS SUBALTERNOS LATINOAMERICANO, FLORENCIA MALLON, JOHN BEVERLEY, TEORÍA DE LA HISTORIA.

\begin{abstract}
This essay analyzes a case study illustrating the reception of the Subaltern Studies analytical perspective, originally developed by the Indian Subaltern Studies Group, by Latin American scholars, and especially, by the Latin American Subaltern Studies Group at the beginning of the 90's. It focuses on the debate regarding the relevance, scope and problems stemming from the application of the subaltern and postcolonial analytical focus in the historical texts of historian Florencia Mallón and cultural critic John Beverly. The author evaluates both sides of the argument, also introducing some points of agreement, dissent and limited concurrence, taking into account the fundamental fact that this debate has developed within the limits of North American academia, limiting the participation of Latin American scholars in equal conditions. The essay concludes with a series of reflections on four general themes in order to assess the problems and challenges stemming from these issues: access to the subaltern corpus, a critique of nationalism in the historiographic operation, subaltern agency and the positivist shadow.
\end{abstract}

Key words: SUBALTERN STUDIES, INDIAN SUBALTERN STUDIES GROUP, LATIN AMERICAN SUBALTERN STUDIES GROUP, FLORENCIA MALLON, JOHN BEVERLEY, THEORY IN HISTORY.

Fronteras de la Historia 7 (2002)

(C) ICANH 
En los últimos años el enfoque desarrollado por el Grupo de Estudios Subalternos de la India ha alcanzado una enorme resonancia en el mundo académico anglosajón y, paulatinamente, ha atraído la atención de diferentes comunidades académicas de otros lugares del mundo. La producción de este grupo de intelectuales, cuyo núcleo central estuvo constituido principalmente por historiadores, ha ejercido una creciente influencia sobre una variedad de campos disciplinarios e interdisciplinarios. La colección editorial denominada Subaltern Studies, que recoge las intervenciones del grupo desde 1982, así como las publicaciones individuales de sus integrantes, muestran la manera sofisticada en que estos estudiosos han entrelazado teoría y práctica investigativa, dentro de una perspectiva política radical ${ }^{1}$.

En el presente ensayo quiero concentrarme en un caso que ilustra la recepción del enfoque subalternista por parte de los estudiosos de Latinoamérica ${ }^{2}$. Con este propósito quiero detenerme en las intervenciones que dos distinguidos latinoamericanistas han realizado sobre la relevancia, alcances, y problemáticas que se desprenden de la aplicación del enfoque subalternista en la escritura de la historia. Se trata específicamente de analizar las intervenciones de la historiadora Florencia Mallon y del crítico cultural John Beverley, ambos autores de fundamentales contribuciones en sus respectivas áreas de especialización ${ }^{3}$. Conviene señalar brevemente dos cuestiones que enmarcan este debate. Primero, el intercambio se mantuvo dentro del nicho de los latinoamericanistas que laboran en el ambiente académico norteamericano, el cual, como se sabe, está compuesto por una población docente multinacional. Segundo, si atendemos a los momentos iniciales de la recepción del enfoque, como sabemos, el autodenominado Grupo de Estudios Subalternos Latinoamericano, organizado a inicios de los años noventa, fue el primer colectivo que dio la bienvenida al enfoque adoptándolo como su emblema de acción. Este grupo estuvo integrado en su mayoría por críticos literarios. Este par de cuestiones informan aspectos presentes en el locus de enunciación del debate que a continuación analizamos.

La "Declaración de Fundación del Grupo de Estudios Subalternos Latinoamericano" se presentó como una suerte de relación programática de una nueva agenda política y académica para la región y sus estudiosos. El manifiesto destacó enfáticamente las limitaciones e inadecuaciones

\footnotetext{
- Una versión preliminar de este ensayo fue presentada en el "I Encuentro Internacional sobre Estudios Culturales Latinoamericanos: retos desde y sobre la Región Andina", que tuvo lugar en la Universidad Andina Simón Bolívar, en Quito, entre el 13 y 15 de junio de 2001. Agradezco los comentarios que posteriormente me brindaron los colegas Pablo Ospina, Carlos Espinosa y María Eugenia Cháves.

${ }^{1}$ Sobre la trayectoria del grupo y sus aportes puede consultarse las evaluaciones de Gyan Prakash, "Subaltern Studies as Postcolonial Criticism", American Historical Review 99, no. 5 (1994); y Dipesh Chakrabarty, "Subaltern Studies and Postcolonial Historiography", Nepantla: Views from South 1, no. 1 (2000).

${ }^{2}$ Varias entregas de la Latin American Research Review, entre 1990 y 1993, dan cuenta de invocaciones, comentarios y debates sobre la recepción del enfoque poscolonial y los estudios latinoamericanos previos al debate que nos ocupa. Florencia Mallon documenta estas discusiones en el artículo que informa este debate.

${ }^{3}$ Parte de la amplia producción de estos autores aparece en la bibliografía citada.
} 
de los paradigmas (marxismo, dependentismo, teoría de la modernización) que han gobernado el análisis social de América Latina. A partir de la denuncia de estas limitaciones, referidas en verdad de manera vaga en el manifiesto, el grupo formuló los objetivos de un nuevo programa de investigaciones que incluía la tarea de realizar "un trabajo arqueológico en los intersticios de las formas de dominación", con el fin de rescatar la agencia o iniciativa de los sectores subalternos, re-conceptualizar la nación y lo nacional, y visualizar de forma no-esencialista la categoría de clase, entre otros objetivos. Se trataba, en definitiva, de mostrar cómo los paradigmas del conocimiento social, incluido el marxismo, habían quedado atrapados en perspectivas elitistas. En su lugar, se decía, la representación de la subalternidad en Latinoamérica está vinculada con la posibilidad de que "el subalterno hable como un sujeto sociopolítico"4.

La primera evaluación general de la recepción del enfoque subalternista en los estudios latinoamericanos (desarrollados en Norteamérica), que incluye una discusión del manifiesto del Grupo de estudios subalternos latinoamericano, fue realizada por la historiadora Florencia Mallon (de la Universidad de Wisconsin) en el contexto de un foro organizado por la American Historical Review, en el cual también participaron el historiador de la India Gyan Prakash (Universidad de Princeton) y el africanista Frederick Cooper (Universidad de Michigan). El artículo de Mallon, titulado "The Promise and Dilemma of Subaltern Studies: Persectives from Latin American History" (1994), se ocupa precisamente de subrayar la potencialidad y de presentar las tensiones que emergen de la propuesta del grupo de Estudios Subalternos de la India, así como de explorar la relevancia que la aplicación que este enfoque tendría para los estudios latinoamericanos. Mallon encuentra que el análisis de la subalternidad, según la "Declaración" del grupo latinoamericanista, está ampliamente desinformado de las contribuciones de la historia social latinoamericana y adolece de un predominio textualista restrictivo. Ambos rasgos, en general, estarían atravesados por un tono de esquematismo programático.

El reclamo de Mallon sobre la manera en que el manifiesto ignora, o invisibiliza, los vibrantes aportes de la historia social en el área latinoamericana, a la luz de la extensa bibliografía que una pléyade de destacados historiadores sociales, entre los que se incluye la autora, han producido sobre una variedad de grupos subalternos (grupos étnicos, campesinos, esclavos, obreros, artesanos, mujeres, etc.), estudiados en diferentes períodos de la historia latinoamericana, resulta enteramente convincente y justificado. Era de esperar que una crítica tan definitiva como la pregonada por la "Declaración", sobre la manera en que se han estudiado

\footnotetext{
${ }^{4}$ La "Declaración de fundación del Grupo de Estudios Subalternos Latinoamericanos" ha aparecido en diversas publicaciones. La versión original en inglés consta en J. Beverley, J. Oviedo y M. Ahorna, eds., The Postmodernism Debate in Latin America (Durham: Duke University Press, 1995). En este ensayo utilizo la traducción al español que hizo Juan Zevallos Aguilar y que fue publicada en Procesos, revista ecuatoriana de historia, no. 10 (1997).
} 
los grupos subalternos latinoamericanos, se basara en un análisis más informado y riguroso de la producción historiográfica latinoamericana y latinoamericanista. Mi adhesión a la crítica de Mallon, sin embargo, se cuida de no confundir la perspectiva de la historia social y el enfoque subalternista. Creo que si bien entre ambos enfoques se presentan translapes, estos mantienen diferencias que los distinguen ${ }^{5}$. El punto básico que muy justificadamente levanta la historiadora Mallon es que en el campo de la investigación histórica latinoamericana el tema del subalterno no era una novedad. Por esta razón, me parece que la introducción del enfoque subalternista necesitaba menos de juicios terminantes, y promesas de nuevos cielos conceptuales, y más de un deslinde riguroso anclado en el reconocimiento crítico de lo que la historia y la antropología, entre otras disciplinas, habían hecho, en regiones como el mundo andino, por ejemplo.

El cuestionamiento de Mallon a la "Declaración" subraya que los desarrollos de la llamada 'historia social desde abajo', variante radical de la historia social, permitieron que esta formulara, a lo largo de los años ochenta, una provechosa crítica al cepalismo, dependentismo, marxismo y teoría del sistema mundial. Nuevamente la crítica de Mallon a este respecto me parece enteramente pertinente. No obstante, creo que se debe señalar que la empresa de revisión crítica de los paradigmas de las ciencias sociales latinoamericanas no fue una empresa escrita predominantemente en idioma inglés, como tiende a sugerir la extensísima bibliografía que documenta el ensayo de esta autora. Más bien se debe precisar que dicha revisión crítica fue desarrollada, a la par, en el norte y en el sur. Los estudios referidos a la región andina que autores como Murra, Spalding, Stern y Larson ${ }^{6}$, asentados en el mundo académico norteamericano, representaron en la teoría y la práctica cuestionamientos y superaciones a los paradigmas dominantes en la historiografía y las ciencias sociales de esos años. Paralelamente a estos desarrollos, un grupo de notables historiadores provenientes de los países andinos, en diálogo con sus colegas de Norteamérica y de Europa, reconfiguraron el pasado de estas sociedades desde una perspectiva histórica sofisticada y plenamente contestaria al statu quo. Autores como Assadourian, Colmenares, Flores-Galindo, único autor citado por Mallon, Rivera Cusicanqui, entre otros, con sus investigaciones cuestionaron los modelos dominantes de la

\footnotetext{
5 Prakash y Chakrabarty han puntualizado algunas de las semejanzas y diferencias entre ambos enfoques. Chakrabarty señala, por ejemplo, que el enfoque subalterno implica, a diferencia de la perspectiva de la historia social "desde abajo": "a) una relativa separación entre la historia del poder y cualquiera de las historias universalistas del capital, b) una crítica de la forma nación, c) una interrogación de la relación entre poder y conocimiento", que incluye al archivo en sí mismo y a la historia como saber ("Subaltern Studies and Postcolonial Historiography", 15). Todas las traducciones del inglés al español que aparecen citadas en este ensayo son de mi autoría, excepto las citas que provienen de la "Declaración" señalada en la nota anterior.

${ }^{6}$ La bibliografía que integra esta y la siguiente nota no es exhaustiva, tan solo desea ilustrar algunas de las contribuciones más relevantes y tempranas. John Murra, Formaciones económicas y políticas del mundo andino (Lima: IEP, 1975). Karen Spalding, De indio a campesino (Lima: IEP, 1974). Steve Stern, Los pueblos indígenas del Perú y el desafio de la conquista española (Madrid: Alianza Editorial, 1986), traducido al español por Fernando Santos, la versión original en inglés apareció en 1982; "Feudalism, Capitalism, and the World-System in the Perspective of Latin America and the Caribbean", American Historical Review 93, no. 4 (1988). Brooke Larson, "Shifting Views of Colonialism and Resistanse", Radical History Review, no. 27 (1983); Colonialismo y Transformación Agraria en Bolivia. Cochabamba, 1500-1900 (La Paz: CERES - HISBOL, 1992), traducido al español por Frederic Vallvé, la versión original en inglés se publicó en 1988.
} 
historia y las ciencias sociales en la región andina y abrieron fructíferas vías de investigación, de las que todavía somos tributarios en el presente ${ }^{7}$.

El segundo cuestionamiento de Mallon está enfilado contra la preeminencia del texto-centrismo desconstruccionista que, en clave Derrideana, según la autora, aparece como principal gesto investigativo de la "Declaración". La desconfianza de Mallon frente al protagonismo del análisis textual le lleva, por contrapartida, a enarbolar un programa de investigación empíricamente informado. La autora advierte una fuerte tensión en la agenda subalternista entre una técnica, informada por perspectivas posmodernas, y una perspectiva política, de corte posmarxista radical. El primer componente de esta tensión se expresa, según Mallon, en una estrecha lectura posmoderna de los documentos, entendidos estos de manera genérica como "textos construídos", cuya lectura no deviene en la obtención de una verdad transparente, si uno se atiene a los reparos de las posiciones posmodernas más extremas. Los críticos literarios habrían asimilado ampliamente este tipo de aproximación posmoderna y la habrían puesto en operación preferentemente en fuentes publicadas. El segundo componente de esta tensión, según Mallon, se expresa en "el interés disciplinario del historiador [con el cual ella obviamente se identifica] de leer los documentos, almacenados en los archivos, como 'ventanas', no obstante neblinosas e imperfectas, de las vidas de las gentes". ${ }^{8}$ Uno puede pensar que este segundo componente de la tensión, con el cual la autora se identifica, está más alineado con una perspectiva política radical que con la aplicación de cualquier lectura técnica de los textos, según aludí líneas atrás.

La presunción de que los documentos que reposan en los archivos no son del todo "textos construidos", en el sentido posmoderno del término, y de que el historiador los usa como "ventanas... neblinosas", al parecer no fue formulada por su autora para defender alguna comprensión de tipo positivista de la labor del historiador. Prueba de ello es que la autora, seguidamente, reconoce que tanto el archivo como cualquier otro campo de investigación

[...] son arenas construídas en las cuales las luchas de poder -incluidas las generadas por nuestra propia presencia [como investigadores]- actúan para definir y obscurecer las fuentes y la información a la cual accedemos".

Su punto de crítica parece dirigirse, más bien, a establecer una distinción entre la problemática que rodea el manejo de las fuentes publicadas de aquellas que no lo son: "los procesos de producción y preservación de las fuentes provenientes de los archivos de las que han sido

\footnotetext{
${ }^{7}$ Carlos Sempat Assadourian, et. al., Modos de Producción en América Latina (Buenos Aires: Cuadernos de Pasado y Presente, 1973); El Sistema de la Economía Colonial (Lima: Instituto de Estudios Peruanos,1982). Germán Colmenares, Sociedad y Economía en el Valle del Cauca (Cali: Universidad del Valle, 1983). Alberto Flores Galindo, Aristocracia y Plebe. Lima, 1760-1830 (Lima: Mosca Azul Editores, 1984); Buscando un Inca (Lima: Editorial Horizonte, 1987). Silvia Rivera Cusicanqui, "Oprimidos pero no Vencidos". Luchas del campesinado aymara y qhechwa de Bolivia, 1900-1980 (La Paz: Hisbol - Esutcb, 1984).

${ }^{8}$ Florencia Mallon, "The Promise and Dilemma of Subaltern Studies: Persectives from Latin American History", American Historical Review 99, no. 5 (1994): 1506.

${ }^{9}$ Ibídem, 1507.
} 
publicadas son distintos. Las relaciones sociales que acompañan la lectura de una u otra son también diferentes". Entonces, "lo que yo objeto", dice Mallon, "es el privilegio del análisis textual y de las fuentes literarias a costa o en desmedro del trabajo de archivo o de campo, tanto como la tendencia a asumir que todos son textos construidos y que, por lo tanto, el uno puede sustituir al otro" $"$.

La crítica anotada fue desarrollada ampliamente en su posterior libro Peasant and Nation. The Making of Postcolonial Mexico and Peru ${ }^{11}$, que se presenta como resultado de más de una década de investigación en archivos de varias latitudes. Este libro constituye un ambicioso y admirable programa de investigación desarrollado con el propósito de historizar al subalterno. El trabajo analiza cuatro procesos de resistencia regional y campesina ocurridos en el s. XIX, en el contexto de invasiones extranjeras. Los dos principales casos estudiados corresponden a la sierra norte de Puebla (1853-1876), en México, a propósito de la invasión francesa; y a Junín, en la sierra central del Perú, durante la invasión chilena en la llamada Guerra del Pacífico (1879-84). También se analizan los casos de Morelos (México) y Cajamarca (Perú).

Las múltiples reseñas y comentarios que Peasant and Nation ha merecido me relevan, en parte, de volver a referir los distintos ámbitos en que la obra contribuye, de manera particular, a la historiografía latinoamericana $\mathrm{y}$, en general, a los estudios latinoamericanos ${ }^{12}$. Solo con el propósito de ilustrar rápidamente los aspectos que la crítica ha destacado de este libro enumero los tres niveles que me parece han concentrado la atención. En primer lugar está el nivel teórico que informa el desarrollo del libro, expresado en la manera reflexiva en que la autora emplea algunos conceptos centrales al análisis social y cultural (v. gr. hegemonía, poder, etc). En segundo lugar se destaca el asunto de la (agency) agencia / iniciativa de los campesinos que, como se desprende de los casos estudiados, no sufrieron pasivamente la dominación y por el contrario fueron capaces de emprender una serie de negociaciones y de esbozar proyectos alternativos a los de las élites. La comprensión de la política de los grupos subalternos, en este caso de los campesinos, se plantea "como una combinación de dominación y resistencia". En tercer lugar, se ha destacado los alcances y las implicaciones de las experiencias concretas analizadas para reconsiderar los procesos más generales de constitución nacional en Latinoamérica y del papel que cumplieron los nacionalismos populares.

Hay un punto adicional que la obra de Mallon convoca a discutir y que hasta el momento no ha tenido la atención que merece. Se trata de la relación entre historiografía y nacionalismo. El asunto que quiero subrayar no tiene que ver con la crítica o impugnación que ha recibido, de

\footnotetext{
${ }^{10}$ Ibídem, 1508

${ }^{11}$ Florencia Mallon, Peasant and Nation. The making of poscolonial Mexico and Peru (Berkeley: University of California Press, 1995).

${ }^{12}$ Entre las principales evaluaciones de Peasant and Nation pueden consultarse los ensayos de John Tutino y Tulio Halperín Donghi, además de la respuesta de la autora en Historia Mexicana XLVI, no. 3 (1996). Entre las reseñas aparecidas en revistas académicas anglosajonas puede consultarse, por ejemplo, la escrita por Nils Jacobsen en la American Historical Review (June, 1995) y la perteneciente a Jeremy Adelman, "Spanish-American Leviatán: State Formation in Nineteenth-Century Spanish America. A Review Article", Comparative Studies in Society and History 40, no. 2 (1998).
} 
manera justificada, el género de las llamadas historias oficiales, por parte de los avances, principalmente, de la historia social latinoamericana. Desde esta perspectiva crítica se sostiene, de manera corriente, que mientras las 'historias oficiales' se caracterizan por ser productos inherentemente limitados a intereses de clase (elitarios), modelados por ideologías nacionalistas de diverso cuño, las obras enlistadas dentro de la corriente de la historia social o económica se presentan investidas de un halo de saber científico. El punto que quiero destacar del libro de Mallon es que si bien participa en cierta medida de esta perspectiva, lo más importante es que también la desborda. En un pasaje de Peasant and Nation, la autora evoca la trayectoria de su empresa de indagación histórica desde el trajín por polvorientos archivos hasta la confección de una escritura histórica alumbrada por la búsqueda de un descentramiento. La autora no se conforma con alistarse en las filas contestarias a las historias del statu quo. Da un paso más allá y se observa a sí misma en el proceso de interrogación del pasado, en un gesto que tiene evidente inspiración posmoderna. Al reconocerse como constructora de esta novedosa narrativa histórica, la autora se descubre poseedora de un poder de representación del pasado y nos dice lo siguiente a este respecto:

[...] estoy demoliendo historias oficiales solo para construir unas de nuevo tipo. No obstante, mis esfuerzos darán frutos sólo si tengo el deseo de escuchar, de abrir mi narrativa a voces e interpretaciones contrarias, a batallar por evitar caer en el papel del narrador omnisciente o positivista ${ }^{13}$.

La distancia que la autora busca tomar de la figura de la narradora histórica omnisciente o positivista, así como el esfuerzo de mirarse en el proceso de mirar el pasado, nos invita a pensar el locus de enunciación de Mallon. Nos convoca a devolver la mirada sobre el nacionalismo y el poder a la propia voz que habla en Peasant and Nation. Esto es precisamente lo que ha hecho Tulio Halperín Donghi en un ensayo que sobre esta obra ha escrito con una agudeza exquisita y sobre el cual volveré a ocuparme en la última sección del presente ensayo.

\section{III}

Uno de los nombres que desde la crítica literaria y cultural ha reflexionado con mayor penetración sobre el enfoque subalterno y el campo de los estudios latinoamericanos ha sido John Beverley. Habiendo sido uno de los fundadores más prominentes del primer grupo de estudiosos que invocó este enfoque como emblema, Beverley articuló, en sucesivas entregas, una respuesta a las apreciaciones críticas de la historiadora Florencia Mallon a la luz de una preocupación más general, y a la vez más compleja, sobre las maneras y las dificultades que el conocimiento académico enfrenta a la hora de buscar representar a los subalternos. La primera reacción de Beverley apareció como una entrevista en la publicación Journal of Latin American Cultural Studies, en 1997. Nuevamente volvió sobre el tema en algunas secciones de su libro

\footnotetext{
${ }^{13}$ Mallon, Peasant and Nation, 20.
} 
Subalternity and Representation (1999), y seguidamente en el artículo de postura "The Dilemma of Subaltern Studies at Duke", en 2000. En lugar de ofrecer un resumen secuencial de las aseveraciones de este autor, seguidamente, establezco los puntos que, en mi opinión, mejor revelan su reacción.

a) En relación al acumulado del estudio sobre los sectores subalternos latinoamericanos, realizado por sociólogos, antropólogos e historiadores, Beverley acepta que esta tarea ha sido cultivada desde hace tiempo, no obstante juzga que ha sido desarrollada "sin necesariamente adoptar una perspectiva subalternista". Puntualiza, además, que si bien varios historiadores sociales habían mostrado preocupaciones políticas y filosóficas parecidas a las de los subalternistas, ninguno había "elevado el tema de la subalternidad al nivel teórico que el Grupo Surasiático lo había hecho" ". Beverley no es explícito en señalar las limitaciones de los historiadores sociales a la hora de estudiar la subalternidad. No obstante la invalidación de los desarrollos de la historia social, a nombre de una perspectiva que se presenta como teóricamente correcta o más avanzada, pareciera reclamar una suerte de vanguardia intelectual o política, o simplemente caer en lo que Hernán Vidal llamó "crítica literaria tecnocrática"15. En verdad si creemos que no hay una única manera de hablar sobre el subalterno, sino varias, entonces lo que se presenta por delante es una tarea de evaluar los desarrollos de estos enfoques y sopesar qué pueden aprender unos de otros. De otro lado, si trascendemos las fronteras de los circuitos académicos y escudriñamos los impactos que este ha experimentado o ha ocasionado en otros campos de la vida social, pueden surgir un conjunto de problemáticas de tanto o mayor interés investigativo. Por ejemplo, uno puede interrogarse por la manera en que las narrativas históricas alternativas (tipo historia social, subalternista o de otro cuño) circulan o son asimiladas, en este caso, por las heterogéneas sociedades andinas contemporáneas. Podríamos preguntar cuál ha sido la recepción de la obra de autores como Germán Colmenares o Steve Stern, de manera específica, en los sistemas escolares, en los núcleos de cultura académica, en los nichos de cultura erudita local, etc. En otras palabras, ¿cómo los subalternos de la periferia han reaccionado, consumido, o han permanecido indiferentes ante las representaciones que sobre los subalternos ha elaborado la historia, la crítica literaria, la antropología, etc? ¿De qué manera los movimientos sociales de los países andinos incorporaron estas representaciones del subalterno? En síntesis estas preguntas rondan la cuestión relativa a la/s manera/s en que los discursos históricos alcanzan una relevancia social o se convierten en discursos social-política o culturalmente significativos ${ }^{16}$.

b) La respuesta a la pregunta de por qué los estudios subalternos encuentran una mayor audiencia inicialmente en el campo de la crítica literaria, y no en la historiografía como se podría haber esperado, encuentra una clave importante en la reflexión que Beverley realiza

\footnotetext{
14 "Negotiating with the Disciplines. A Conversation on Latin American Subaltern Studies", with James Sanders, Journal of Latin American Cultural Studies 6, no. 2 (1997): 235-6.

${ }^{15}$ Esta se refiere al resultado que tiende a ocurrir luego de la introducción de un nuevo paradigma analítico, el acumulado de esfuerzos semejantes realizado en el pasado se invalida o se coloca en la penumbra.

${ }^{16}$ Mabel Moraña en su ponencia presentada al Encuentro de Estudios Culturales de Quito, de 2001, indagaba por la relevancia social de los discursos literarios.
} 
sobre la trayectoria de los estudios literarios y en la suerte de teorización de la crisis de la crítica literaria, que muy agudamente formula. Este autor señala que a partir de la consideración de los desafíos que planteó La Ciudad Letrada (1982), escrita por el crítico literario uruguayo Angel Rama, la genealogía de la empresa literaria descubrió una perenne imbricación con las estructuras de poder vigentes desde su origen en la tradición letrada colonial. La revisión del proyecto de la empresa literaria, como creación, crítica o forma pedagógica, desembocó en una abierta crisis en el contexto del ocaso de los proyectos de liberación nacional que se escenificaron en Centroamérica en los años ochenta. A la luz de dicha crisis y utilizando un instrumental proveniente del pos-estructuralismo y de la semiótica, los críticos culturales radicales habrían desbordado los marcos de comprensión más formales de la literatura y empezaron a interesarse por una consideración más general del rol de las instituciones culturales en la creación de relaciones de poder, clase y diferenciación étnica. En ese contexto, según anota Beverley, se operó el giro subalternista de los críticos literarios, que "fue una forma de teorizar los límites de nuestro propio trabajo". Empero, "nada similar sucedió en la historia"17.

c) Como sabemos Peasant and Nation muestra que las comunidades campesinas tuvieron un papel decisivo en los procesos de formación estatal en México y Perú. Precisamente por esto Beverley afirma que la narrativa de Mallon se desarrolla dentro de una suerte de "proyecto representacional", en virtud del cual los subalternos alcanzan finalmente un lugar dentro del gran fresco nacional. Este logro historiográfico, desde la perspectiva de la historia social, se convierte a ojos de Beverley en una limitación, en la medida que una narrativa histórica de este tipo no es otra cosa que la "biografía del estado-nación". Beverley cree que en vez de mostrar a plenitud la separación que había entre los subalternos y el proyecto de estado nacional, la narrativa de Mallon "sutura una brecha social y conceptual que mejor sería dejarla abierta". Siguiendo al historiador Ranajid Guha, Beverley sostiene que en este caso la tarea historiográfica debía mostrar "la manera en que la insurgencia campesina 'interrumpe' la narrativa de la formación estatal"18.

d) La crítica anterior nos remite a un problema más amplio sobre la dificultad de representar al subalterno o, dicho de otra manera, nos aproxima a constatar los límites del trabajo del historiador. Al tratar esta dificultad Beverley evoca la debatida interrogante que hace tiempo lanzara la crítica cultural Gayatri Spivak: “¿Puede el subalterno hablar?” La interrogante de Spivak apuntaba a que si el subalterno pudiera hablar - esto es hablar en una forma que realmente ejerciera un impacto- entonces no habría sido subalterno. Siguiendo esta perspectiva Beverley cuestiona "¿si es realmente posible representar al subalterno desde la posición disciplinaria del historiador o del crítico literario, esto es desde la posición institucional de la cultura dominante?" Su respuesta es que debido a la asimetría entre la posición del historiador o del crítico literario y la del subalterno, hay tanto un límite epistemológico y ético, como una brecha, que no se puede salvar entre ambas posiciones. Por esta razón Beverley sostiene que el meollo del trabajo intelectual o académico, según la perspectiva de los estudios subalternos,

\footnotetext{
${ }^{17}$ Beverly, "Negotiating", 235.

${ }^{18}$ Beverly, "Negotiating", 241-3 y Subalternity and Representation. Arguments in Cultural Theory (Durhan: Duke University Press, 1999), 36.
} 
[...] no es tanto [representar] al subalterno como un sujeto socio-histórico concreto, sino [se encuentra en] la dificultad de representarlo como tal en nuestro discurso disciplinario y en la práctica dentro del mundo académico ${ }^{19}$.

e) Finalmente, Beverley encuentra que Mallon a pesar de los esfuerzos que despliega ve la historia de una manera positivista, en virtud de la cual ella se sitúa en el centro del acto de representar y conocer. En esta perspectiva Mallon casi no abandona el rol de narradora omnisciente. Para representar un diálogo verdadero, Beverley argumenta, y aquí debemos retomar los puntos de los acápites anteriores, ella habría tenido que desarrollar una narrativa que fuera interrumpida por otras formas de narrativa orales o escritas provenientes de los actores del pasado o de los intelectuales locales. En lugar de esto, Mallon en Peasant and Nation, lo que hace

[...] es escribir [...] la biografía del estado-nación, mostrando en esa narrativa la presencia de formas de agencia subalterna que otros relatos $-\mathrm{v}$. gr. las historias oficiales- podrían haber ignorado. No obstante, de esta forma, el marco de la nación y de la inevitabilidad de su presente (tanto como la autoridad de la historia y la propia autoridad de Mallon como historiadora) permanece intacto ${ }^{20}$.

¿Cómo podría Mallon haber sido consecuente con sus propósitos? La respuesta que Beverley proporciona a este respecto es breve y, especialmente, limitada a exaltar el modelo de trabajo historiográfico que Ranajid Guha desarrolló particularmente en Elementary Aspects of Peasant Insurgency in Colonial India (1983). Dicha respuesta, como ya sabemos, tiene que ver con la manera en que la narrativa de Mallon y de la construcción del estado-nación podrían haber sido "interrumpidas" por las voces locales. Según Beverley, Guha "rompe con la diacronía" de la narrativa del estado-nación al momento de representar las insurgencias campesinas, de manera modélica, mostrando cómo a partir de la intransigencia y resistencia campesina, el Estado se ve en la necesidad de modificar sus estrategias y formas de trato con los subalternos. Sin embargo, la narrativa de Guha habría cuidado, según Beverley, de preservar que la representación histórica de las insurgencias campesinas muestre la posibilidad de que ellas contengan una historia que fue sepultada y olvidada, mostrando una forma de Estado distinta y otra forma de tiempo, por ejemplo.

\section{IV}

En esta última sección quiero concluir esbozando determinados problemas generales y algunos desafíos que emergen de los asuntos tratados. Como hemos visto, este debate se ha desenvuelto dentro de los términos del latinoamericanismo norteamericano. En diferentes partes he ido deslizando adhesiones, deslindes o acuerdos parciales con los argumentos presentados por sus

\footnotetext{
${ }^{19}$ Beverly, Subalternity, 1-20 y "Negotiating", 253-254.

${ }^{20}$ Beverly, Subalternity, 36-37.
} 
autores. Estoy persuadido de que los estudiosos de Latinoamérica, tanto los que trabajamos en el sur como los que laboran en la metrópoli, podemos aprender del intercambio reseñado y, mucho más, de la manera en que reflexionemos sobre los puntos cruciales del mismo. Seguidamente me ocupo de cuatro problemas generales que emergen de mi lectura crítica del intercambio analizado. Primeramente, llamo la atención, de manera breve, sobre el acceso al corpus subalternista y el tema de la acción o iniciativa del subalterno. Seguidamente considero, de manera más extendida, el tópico de la crítica al nacionalismo en la operación historiográfica; $\mathrm{y}$, concluyo considerando la problemática del acecho del positivismo.

a) En primer lugar cabe meditar sobre el asunto del idioma en el que se ha desarrollado (o difundido) el enfoque subalterno y en el que se ha formulado el debate revisado. Como sabemos, el asunto de que la producción académica mencionada discurra en idioma inglés forma parte del hecho que dicha lengua se convirtió en el principal idioma académico del mundo contemporáneo y de que el idioma español ocupa un lugar secundario en este contexto. A la hora de revisar la cronología de las traducciones de los autores subalternistas al español salta a la vista lo tardío y limitado de tal empresa, aunque se haya dinamizado en los últimos años. Todavía estas traducciones se pueden contar con los dedos de una mano ${ }^{21}$. No obstante, sorprende que ninguno de los participantes en el debate, de quién habla por el subalterno en Latinoamérica, se haya ocupado del acceso de la audiencia académica e intelectual de América Latina al enfoque subalterno. Llamo la atención sobre este asunto no tanto porque quiera lamentarme de las deficiencias de la enseñanza de una segunda lengua, en este caso del idioma inglés, en los sistemas educativos latinoamericanos, reclamar el descuido de las casas editoriales del mundo hispanoamericano de traducir la producción subalternista, o señalar las tensiones o inconsistencias del latinoamericanismo progresista de la academia metropolitana. Lo que pretendo más bien en este caso es subrayar el acceso diferenciado que los académicos o intelectuales del sur tienen respecto a ese tipo de debates y la consiguiente configuración de situaciones de subalternidad en las que se ven envueltos segmentos importantes de la audiencia intelectual latinoamericana por este motivo.

El asunto del idioma y del acceso diferenciado a los debates poscoloniales tiene que ver concomitantemente con la problemática del locus de enunciación y de las implicaciones de si se habla desde o sobre Latinomérica. Hablar "desde" o "sobre" me parece que tiene que ver en el caso del debate Mallon-Beverley, entre otros rasgos, con quiénes estos autores consideran sus interlocutores centrales en el debate académico y, fundamentalmente, con la manera en que la región latinoamericana cuenta a la economía de dicho debate, sea como proveedora de objetos de investigación o como productora de conocimiento. Por esta razón si bien es posible evaluar el intercambio entre Mallon y Beverley acerca de quien habla sobre el subalterno, en el caso de la recepción del enfoque subalternista por parte de los estudiosos cuyo locus de enunciación se configura a partir de algún lugar de Latinoamérica, resulta prematuro intentar alguna evaluación

\footnotetext{
${ }^{21}$ Silvia Rivera Cusicanqui y Rossana Barragán, comp., Debates poscoloniales. Una introducción a los estudios de la subalterninadad (La Paz: Historias - Sephis, 1997); el número monográfico Historia y Grafia, no. 12 (1999); y, Saurabh Dube, coord., Pasados Poscoloniales (México: El Colegio de México, 1999), disponible para consulta también en http:/www.clacso.org.
} 
que siga las líneas del debate aludido. No obstante, queda pendiente la realización de una evaluación más sistemática sobre la manera en que la historia, la crítica literaria y las ciencias sociales, en general, en Latinoamérica, han representado al subalterno antes de la importación de enfoque subalterno, o a la luz de los interrogantes que este presenta. En todo caso, debe quedar claro que además de las contribuciones de Florencia Mallon y John Beverley existe una creciente bibliografía en idioma inglés sobre la historia y la cultura de Latinoamerica, en la que participan destacados estudiosos y teóricos latinoamericanos, que han adoptado explícitamente el enfoque subalterno o han sido fuertemente influidos por él y cuyos trabajos no han sido mencionados en este ensayo.

b) El asunto crucial de la acción, iniciativa o agencia del subalterno ha sido desarrollado, en la agenda subalternista, según Gyan Prakash, en medio de una tensión entre una posición que busca recuperar al subalterno "como un sujeto fuera del discurso de la elite", y otra según la cual "el análisis de la subalternidad [se observa] como un efecto de sistemas discursivos"22. Tengo la impresión de que los planteamientos de Mallon y Beverley, respecto al tema de la agencia, reproducen en cierta medida esta tensión. La reflexión que Fernando Coronil elabora sobre la reputada interrogación de Spivak de si el subalterno puede o no hablar, me parece, introduce una manera provechosa de trabajar la tensión referida y permite, como dice este autor, "contrarrestar antes que confirmar el efecto silenciador de la dominación". Coronil propone que "veamos al subalterno no como un sujeto soberano que activamente ocupa un lugar asignado, tampoco como un vasallo resultado de los efectos dispersos de múltiples determinaciones externas, sino como un agente de la construcción de su identidad que participa, bajo determinadas condiciones dentro de un campo de relaciones de poder, de la organización de una posicionalidad y subjetividad múltiple" ${ }^{23}$.

Quiero resaltar que en la perspectiva de Coronil la subalternidad es un concepto "relacional y relativo". Tiene el carácter relacional porque al igual que la dominación, la subalternidad no es una característica inherente o de tipo esencialista: "la subalternidad define no el ser de un sujeto sino el estado de sujeción de un sujeto". La subalternidad se caracteriza por ser relativa debido a que "hay momentos y lugares en los cuales los sujetos aparecen en el escenario social como actores subalternos, así como esos mismos actores pueden jugar un rol de dominadores en otros contextos". No resulta extraño, por lo tanto, que en un contexto específico un determinado actor sea subalterno frente a otro y, a la vez, dominador de un tercero ${ }^{24}$. Creo que la contribución de Coronil permite reflexionar la "agencia" de los actores históricos al margen de la romantización política del subalterno o de su enmudecimiento teórico. Pensar al subalterno en perspectiva histórica como parte de un efecto discursivo sin perder de vista su rol de agente, permite interrogar de manera más compleja y provechosa la historia como un proceso con sujetos que hacen la historia en condiciones que ellos no han elegido sino que les han sido legadas.

\footnotetext{
${ }^{22}$ Prakash, "Subaltern Studies", 1480-1481.

${ }^{23}$ Fernando Coronil, "Listening to the Subaltern: the Poetics of Neocolonial States", Poetics Today 15, no. 4 (1994): 644,645 y 648.

${ }^{24}$ Ibídem, 648-649.
} 
c) En tercer lugar quiero retomar al tema del entrampamiento de la historia como "biografía de la nación" y la demanda de que la narrativa histórica debe "interrumpir" el relato (elitista) de la nación para alcanzar un estatuto efectivamente subalternista, según la insistencia de Beverley. Como hemos visto la tesis de este autor parte del supuesto, más alegado que sustentado, de que inclusive las narrativas más radicales de los historiadores sociales se han visto atrapadas en la perspectiva de un "proyecto representacional" de la nación. De acuerdo con este proyecto

[...] nada cambia en el pasado porque el pasado se ha ido, pero tampoco nada cambia en el presente, en el sentido que la historia como tal no modifica las relaciones de dominación y subordinación existentes ${ }^{25}$

En el caso del proyecto de Mallon, y por extensión de la historia social latinoamericana, en la biografía del estado-nación se busca incluir la presencia de formas de agencia subalterna que fueron previamente omitidas de las historias oficiales. No obstante este aparente logro, Beverley sostiene que este tipo de inclusión "deja el marco de la nación y la inevitabilidad de su presente (tanto como la autoridad de la historia [y la del historiador]) intacta". ${ }^{26}$

La crítica de Beverley me parece de un gran potencial analítico aunque advierto en ella un apresuramiento. Antes de subrayar la faceta germinal de esta crítica, me detengo en su flanco espinoso. Un cuestionamiento tan fuerte sobre las limitaciones de la empresa de la historia social necesita de una demostración o documentación de mayor amplitud y rigor. Considero inadecuado mantener este como un juicio conclusivo y propongo la conveniencia de reformularlo en términos más exploratorios. ¿En que medida las representaciones de los grupos subalternos, elaboradas por la historia social latinoamericana, han alterado (o no) la comprensión elitista de los procesos de formación nacional? ¿De qué manera el panteón nacional creado por las historias oficiales, compuesto por una galería de conquistadores, presidentes, generales, obispos, y notables, se ha visto trastocado por el ingreso de un cortejo de representantes de grupos anteriormente ausentes, v. gr., indígenas, obreros, campesinos, y últimamente mujeres, presentados por los relatos de la historia social y económica que se desarrolló desde fines de los años setenta? ¿Cómo circularon y fueron asimiladas las narrativas históricas que buscaban democratizar el pasado en el contexto tremendamente inequitativo de las heterogéneas sociedades andinas? Estas preguntas, están limitadas, y esto no debe perderse de vista, a la producción histórica académica o profesional y por lo tanto dejan de lado otros numerosos e importantes espacios en que la historia también se produce, y ejerce un impacto más masivo, bien sea a través de los medios de comunicación, el cine, los rituales cívicos, los museos, etc.

La conjetura de Beverley sobre los límites de la historia social se enlaza con el supuesto de que la historiografía no puede alterar el pasado ni modificar las situaciones de poder en el presente. Este supuesto sobre los usos que los actores sociales hacen de las representaciones del pasado, de forma general, luce esquemático y desinformado de una creciente literatura que ha tendido

\footnotetext{
${ }^{25}$ Beverley, Subalternity, 33-36.

${ }^{26}$ Ibídem.
} 
puentes entre historiografía, memoria, política e identidades sociales. Esta literatura muestra que las representaciones del pasado constituyen una materia de disputa y que los actores dirimen situaciones de poder, en un determinado presente, a partir de procesos de resignificación y de apelación a situaciones o eventos pasados, que resultan relevantes a dichas pugnas. Como resultado de estos procesos el pasado y el presente se transforman. Esta creciente literatura tiene un antecedente ya clásico, en el caso de los países andinos, en el célebre libro del historiador venezolano Germán Carrera Damas, El culto a Bolivar (1973), el cual inspiró algunos ensayos, escritos en los años ochenta sobre este tema para los casos de Colombia y Ecuador ${ }^{27}$. De otro lado, un rico abanico de estudios que escudriñan la dialéctica y la interdependencia entre pasado y presente, en distintos momentos históricos y lugares geográficos, ha aparecido en una floreciente literatura contemporánea. Antropólogos históricos como Trouillot o Rappaport, e historiadores como MacCormack y Espinosa, ofrecen algunos ejemplos estimulantes de investigación en esta línea de reflexión ${ }^{28}$. A partir de la consideración del poder como elemento constitutivo de la elaboración de los relatos, Trouillot rastrea, por ejemplo, la manera en que los silencios y olvidos se despliegan en el proceso de producción histórica, desde el momento de formación de las fuentes y archivos, hasta la configuración y circulación de narrativas históricas. Rappaport establece los usos de la historia por parte de un determinado grupo indígena, quien reinventa una tradición en el contexto de un proceso de etnogénesis. MacCormack rastrea la hermeneútica que precede a las crónicas españolas en la figuración del pasado indígena, así como la manera en que las voces andinas enuncian su pasado a la luz de las constricciones de un presente colonial. Espinosa, por su parte, explora los usos del pasado inca formulados por las élites indígenas norandinas siguiendo los parámetros imperiales para alcanzar prevendas y títulos reales. Todos estos casos nos muestran un panorama más matizado y complejo de las relaciones entre pasado y presente.

Volviendo a la faceta germinal que se desprende de la crítica de John Beverley, me gustaría tomar su idea nuclear como punto de partida para enunciarla en términos, más a mi gusto, de una interrogación: ¿Cuál es la relación entre el ejercicio de escritura de la historia, el nacionalismo y los contextos de poder? ¿Se puede escribir un relato histórico desentendido de las constricciones del nacionalismo en cualquiera de sus variantes? ¿De qué manera las constricciones nacionales operan en la indagación histórica cuando esta se formula desde algún lugar académico periférico o metropolitano? No es mi intención ofrecer una respuesta en el marco de este ensayo a estas preguntas cruciales, pero creo que conviene explicitarlas para no

\footnotetext{
${ }^{27}$ Roland Anrup y Carlos Vidales, "El padre, la espada y el poder: La imagen de Bolívar en la historia y en la política", en Simón Bolívar 1783-1983:Imagen y presencia del libertador en estudios y documentos suecos (Estocolmo: Instituto de Estudios Latinoamericanos, 1983); Enrique Ayala Mora, "Tendencias del desarrollo del culto a Bolívar en el Ecuador", ponencia presentada al IV Encuentro de ADHILAC, Bayamo, Cuba, julio de 1983.

${ }^{28}$ Michel-Rolph Trouillot, Silencing the Past. Power and the Production of History (Boston: Beacon Press, 1995); Joanne Rappaport, Cumbe Reborn. An Andean Ethnography of History (Chicago: Chicago University Press, 1994); Sabine MacCormack, “"En los tiempos muy antiguos...' Cómo se recordaba el pasado en el Perú de la colonia temprana", Procesos. Revista ecuatoriana de historia, no. 7 (1995); Carlos Espinosa, "La mascarada del Inca: una investigación sobre el teatro político en la colonia", en Miscelánea Histórica Ecuatoriana, II, (Quito: Museos del Banco Central, 1989) y "El retorno del Inca: Los movimientos neoincas en el contexto de la intercultura barroca", Procesos, revista ecuatoriana de historia, no. 18 (2002).
} 
perder de vista el territorio que deambulamos. En vista de que la crítica de Beverley apunta al desafío específico de escribir la historia de la formación nacional de una manera diferente, cabe entonces plantear la interrogación de cómo se puede escribir un relato que "interrumpa" la teleología del Estado-nación. Por el momento voy a dejar de lado la consideración de si las historias sociales y políticas del tipo que Florencia Mallon ha desarrollado, o que otros autores han producido, como el colombiano Alfonso Munera, el chileno Alfredo Jocelyn-Holt Letelier, o el ecuatoriano Enrique Ayala Mora, convergen o contestan la teleología del Estado-nación. Me parece que ese es un asunto, como he indicado líneas atrás, que merece una detenida consideración y del que no me ocupo aquí.

La producción de una narrativa histórica que sea disonante del modelo de "biografía del Estadonación" aparece inicialmente como un reto. El historiador Prasenjit Duara quizás expresa este desafío con más claridad al llevar a la práctica en su trabajo la aspiración de "rescatar la historia de la ideología del Estado-nación" "29. En esta línea de escribir una historia explícitamente rebelde a las constricciones teleológicas de la ideología del Estado-nación, algunas recientes contribuciones a la historia latinoamericana han llevado también a la práctica lo que para Beverley era el objetivo de un nuevo programa. Entre esas contribuciones cabe mencionar los sendos estudios de José Carlos Chiaramonti, Marc Thurner y Fernando Coroni ${ }^{30}$. El primero escrito desde el marco de una renovada historia política y conceptual, y los siguientes desde un marco explícitamente subalternista. Chiaramonti documenta de manera magistral el vocabulario político, y las realidades que este refiere, del Virreinato del Río de la Plata, desde el período colonial tardío hasta el período formativo del Estado argentino, a mediados del s. XIX. En este contexto, el autor analiza las formas de identidad política pre-nacionales y germinalmente nacionales a contrapelo de la representación que de sí mismo elaboró ulteriormente la ideología del Estado-nación argentino. Thurner, por su parte, no desea limitarse a recobrar la voz del subalterno, sino más bien a historizar a los actores que fueron anatemizados por la imaginación política de los criollos decimonónicos en el Perú poscolonial, mediante el ejercicio de "imaginar históricamente a las comunidades inimaginadas". Su estudio muestra cómo los criollos revivieron un distante pasado Inca, al tiempo que "selectivamente imaginaron una comunidad política que imposibilitaba imaginar a las mayorías como agentes políticos"31. La disyuntiva poscolonial de los campesinos andinos fue buscar inclusión en los márgenes de la exclusión. De otro lado, Coronil devela el proceso histórico de formación estatal en Venezuela, entre la dictadura de Gómez y la caída de Pérez, a contrapelo de la poderosa deificación experimentada por el Estado venezolano durante el período de estudio. El autor presenta una suerte de etnografía del proceso, y de sus implicaciones políticas y culturales, mediante el cual el Estado investido de poderes "mágicos" reconvierte al país en una "nación petrolera", en el contexto del desarrollo de una "modernidad subalterna". La obra no solo muestra las interrupciones que

\footnotetext{
${ }^{29}$ Prasenjit Duara, "Historicizing National Identity, or Who Imagines What and When", en Geoff Eley y Ronald Grigor Suny, eds., Becoming National. A Reader (Oxford: Oxford University Press, 1996), 152.

${ }^{30}$ José Carlos Chiaramonti, Ciudades, provincias, estado. Orígenes de la Nación Argentina (Buenos Aires: Ariel, 1997); Marc Thurner, From Two Republics to One Divided (Durham: Duke University Press, 1997); Fernando Coronil, The Magical State (Chicago: University of Chicago Press, 1997).

${ }^{31}$ Thurner, From Two Republics, 151.
} 
experimentó la "biografía del Estado-nación" venezolano sino los cortocircuitos del proceso histórico con dicha ideología y con la ideología eurocéntrica de la modernidad.

Dejando el marco de la historiografía latinoamericana y volviendo la mirada a uno de los autores del núcleo central del enfoque subalterno, en la perspectiva de ilustrar una manera de escribir historia al margen de la ideología del Estado-nación, creo que puede resultar tan instructivo como inspirador prestar atención al libro de Shahid Amin (Event, Metaphor, Memory. Chauri Chaura 1922-1992) ${ }^{32}$. Este autor escribe sobre un amotinamiento campesino ocurrido en 1922 en la localidad de Chauri Chaura, al norte de la India, que ocasionó la muerte de un grupo de gendarmes policiales, al grito de viva Gandhi, y que concluyó con el posterior juicio y condena a muerte de los campesinos involucrados. El evento fue posteriormente excluido y subsiguientemente reintroducido en la historia oficial del nacionalismo indio, convirtiéndose en uno de sus acontecimientos emblemáticos. Lo verdaderamente distintivo de este estudio es que su autor se ocupa del amotinamiento en una doble perspectiva: lo analiza como un evento y como una metáfora. Esto significa estudiarlo, a la vez, como historia y como memoria. Así, Amin examina el acontecimiento de Chauri Chaura como un evento protagonizado por actores históricamente situados. Simultáneamente rastrea de qué manera dicho evento se convirtió en una metáfora nacionalista. Esto significa explorar históricamente los procesos de significación y resignificación que experimentó el evento, gracias a los cuales otros actores históricamente situados excluyeron y luego reintrodujeron el episodio en la historia nacional. El penetrante análisis de Amin nos acerca a las maneras en que se elaboran y reelaboran las historias nacionalistas, las formas en que se construyen pasados compartidos y, a la vez, las maneras en que se "induce una amnesia nacional selectiva". La indagación histórica de Amin incluyó tanto el análisis de fuentes oficiales como las que recolectó mediante historia oral en el trabajo de campo. No obstante, como nos dice, "concientemente he rehuido usar la historia oral como un condimento para animar la evidencia documental" [...] "El trabajo de campo en este libro no fue emprendido para reemplazar el archivo colonial y nacionalista. En su lugar, fue situado dentro de una compleja relación de variación respecto del archivo oficial". Se trata, entonces, de leer cada fuente como parte de una red entrelazada o imbricada de narrativas, por tanto "la incongruencia con los hechos conocidos no ha sido interpretada como una falla de la memoria, sino como un necesario elemento en el proceso de construcción del relato de Chauri Chaura" ${ }^{, 3}$.

El resultado final, sostiene Amin, no constituye la elaboración de una narrativa de Chauri Chaura completamente alternativa a la versión oficial. Los testimonios de los descendientes de Chauri Chaura no fueron inmunes a las construcciones discursivas que generó el poder hegemónico y que se expresaron en el veredicto oficial del juicio y en la narrativa histórica nacionalista. Sin embargo, en otro plano, la obra de Amin es enteramente diferente puesto que el examen de las circunstancias que modelan "la amnesia selectiva oficial" permite que su estudio esté atento a los silencios sobre los que se monta la narrativa oficial. Según Gyan

\footnotetext{
${ }^{32}$ Shahid Amin, Event, Metaphor, Memory. Chauri Chaura, 1922-1992 (California-Oxford: University of California Press, 1995).

${ }^{33}$ Ibídem, 194-198.
} 
Prakash, una particularidad del notable estudio de Amin es que este no busca estructurarse como el relato más completo de los hechos. Por el contrario, considera "los vacíos, contradicciones y ambivalencias" de la evidencia como "componentes constitutivos" de todos los relatos históricos nacionalistas. Amin emplea la memoria como "un dispositivo que, a la vez, disloca y reinscribe el registro histórico". Prakash considera que la narrativa de Amin tampoco está motivada por recuperar al subalterno como un sujeto autónomo. En ella, más bien, el subalterno aparece como "una presencia obstinada", por cuya razón forman parte de la nación pero a la vez están fuera de ella $\mathrm{a}^{34}$.

d) Como destaqué previamente en la segunda sección de este ensayo, la historiadora Florencia Mallon, en Peasant and Nation, desarrolla una crítica a la manera positivista de desarrollar la labor de los historiadores. Al tiempo que se observa a sí misma en la labor de producción histórica, la autora muestra una explícita reticencia a convertirse en una narradora omnisciente y apuesta por desarrollar una perspectiva de trabajo dialógica, que le permita escuchar, dialogar, interpretar y dar un lugar, en su narrativa, a las voces de los subalternos y de los intelectuales locales. John Beverley, por su parte, como hemos visto, argumenta que el intento de Mallon de alejarse del modelo de relatora omnímoda no alcanza a ser plenamente consecuente $\mathrm{y}$, por lo tanto, sucumbe ante el acecho positivista que, según sugiere, aparece fuertemente enraizado en la empresa historiográfica en general. Parte de ese legado positivista tiene que ver con la autoridad que reclama la disciplina histórica y sus practicantes y las bases en que se fundamenta tal autoridad.

La influencia o pervivencia del positivismo en la empresa historiográfica y en otros ámbitos analíticos es un tema de mayor complejidad del que aquí puedo apenas esbozar. Por el momento quiero concentrarme en el penúltimo capítulo de Peasant and Nation que está dedicado a examinar el relato elaborado por una historiadora local como punto de partida del análisis de una problemática más general sobre intelectuales locales, hegemonía y política nacional. Me detengo en este pasaje porque permite, a la vez, ilustrar los términos en que Mallon analiza la voz de una intelectual local y considerar el asunto de las implicaciones positivistas en que su análisis incurriría, a su pesar. La materia que informa este fascinante capítulo, intitulado "Quién decide a quién corresponde estos huesos" (traducción libre de "Whose Bones Are They, Anyway, and Who Gets to Decide"), arranca con el seguimiento del destino que han tenido unas osamentas encontradas en la plaza central de Xochiapulco (Puebla), el significado que Donna Rivera, una profesora jubilada e historiadora local, atribuye a dichos huesos en relación a la historia nacional de México y la relectura que Mallon desarrolla sobre la interpretación de Rivera. A partir de este episodio Mallon sitúa el relato de los huesos en el contexto del período posrevolucionario del decenio de 1930 y examina de manera novedosa el papel contradictorio de los intelectuales locales como mediadores de proyectos hegemónicos o contrahegemónicos, igualmente se detiene en los rituales e historias orales locales observados como espacios de confrontación. El asunto de los huesos de la plaza de Xochiapulco se torna contencioso a la hora de atribuir una identidad a los mismos. La versión oficial, consagrada por Donna Rivera,

\footnotetext{
${ }^{34}$ Prakash, "Subaltern Studies", 1488-1489.
} 
establece que las osamentas correspondían a los soldados franceses y austriacos que invadieron México a mediados del decenio de 1860 y que cayeron en una emboscada a manos de los defensores de Xochiapulco.

En el desarrollo de su análisis, Mallon se confronta de manera transparente y explícita con el manuscrito de Donna Rivera.

He usado [dicho manuscrito, dice Mallon] como un texto central de mi reconstrucción de la historia local, no obstante yo he adoptado una perspectiva analítica más omnisciente derivada de mi acceso más vasto a la documentación archivística. Bajo estas circunstancias me resulta casi imposible no transformar su trabajo en folklore, a pesar inclusive de que sitúo la discusión como un diálogo entre intelectuales. Si ella está correcta en uno u otro pasaje, yo lo reconozco, pero si no lo está, mi información demuestra su error. Yo ejerzo el poder en mi posición como intelectual al no permitirle [en mi análisis] su respuesta ${ }^{35}$.

Seguidamente Mallon indica que Rivera, en su rol de intelectual local, también disfruta de un poder que tal posición le concede y que resulta similar al de ella aunque en otra esfera.

Si Beverley hubiera analizado este pasaje de la obra de Mallon quizá sus juicios sobre el tópico del/a historiador/a como narrador/a omnisciente se hubieran matizado. Como se ve Mallon concede un lugar en su narrativa a la voz de Rivera. Tampoco se puede alegar que la voz de Donna Rivera aparezca subrepresentada en el análisis de Peasant and Nation. Creo que el problema es de otro tipo pues, en verdad, Mallon registra extensamente la voz de Rivera: muestra la inicial desconfianza de Rivera; la manera en que ella negocia la posibilidad de brindarle acceso a su manuscrito; discute su idea central respecto a que los huesos pertenecían a los invasores y analiza las posibles condiciones en que probablemente surgió esa elaboración; explora la manera en que la hegemonía nacional trabaja en los ámbitos locales, v. gr. Xochiapulco, incorporando de manera selectiva sus memorias locales, en este caso el evento de la nacionalidad de los huesos. En suma, para ser justo, Mallon realiza un sofisticado y atractivo análisis de la elaboración de uno de los "mitos" que informa las "historias oficiales" nacionales, permitiéndonos observar los engarces de lo local con lo nacional y el rol de los intelectuales en los juegos de poder y conocimiento que ocurren no en el ámbito más limitado del mundo académico, porque Rivera no es una intelectual de ese tipo, sino en el más amplio de la cultura política nacional. No obstante, el análisis de Mallon sucumbe a la tentación positivista aunque no enteramente por las razones que alega Beverley.

Tulio Halperin Donghi señala a este respecto dos confusiones que en parte pueden hacerse extensivas a la crítica de Beverley. Señala, en primer lugar, que un autor, en general, sea este historiador o científico social, cree disfrutar de una indisputada soberanía con respecto a un

\footnotetext{
${ }^{35}$ Mallon, Peasant and Nation, 277.
} 
objeto de estudio aparentemente pasivo. No obstante, esta ingenua o vanidosa suposición desconoce que "su objeto es capaz de devolverle la mirada. En el caso de Mallon, dice,

[...] esa soberanía de la que disfruta como constructora de narrativas es la más compartida de todas; a su modo la ejerce también cualquier silencioso vecino de Xochiapulco a quien basta una mirada para clasificarla como [una] "gringa entrometida". 36

En segundo lugar, Halperín Donghi postula que este primer mal entendido oculta otro de más bulto:

[...] de ver a las narrativas ajenas como productos históricos dotados, a lo sumo, de validez relativa a su marco histórico, y a la propia como válida de acuerdo con el más antiguo criterio de verdad que la define como adecuación de la idea a la cosa [...] En suma, [nos dice] mientras Donna Rivera puede tener opiniones acerca de esos huesos, Florencia Mallon está segura de que sabe la verdad sobre ellos [...] Si Mallon teme beneficiarse injustamente con un exceso de poder no es entonces porque descubra que, en ese diálogo que no llega a ser tal, ella tiene la última palabra, sino porque está convencida -aunque se abstenga de confesarlo aun a pesar de sí misma- de que esa palabra se funda en un saber más sólido que el de su antagonista ${ }^{37}$.

El tema de cómo se lee la evidencia o, cambiando de registro, de cómo el historiador aprende a escuchar la voz de respuesta del documento constituye una de las problemáticas centrales de la empresa historiográfica. Esta problemática aparece teñida por la discusión entre una lectura de la evidencia a base de una perspectiva positivista o anti-positivista. En el escenario intelectual contemporáneo, el rechazo al positivismo se ha confundido con la aceptación de un escepticismo o relativismo de tono posmoderno. El historiador Carlo Ginzburg ha alertado con agudeza sobre esta confusión señalando una continuidad entre el positivismo y sus detractores posmodernos. Ginzburg advierte que la evidencia, desde el marco positivista, fue considerada como una ventana que registraba con transparencia la realidad, una vez que se evaluaba la fiabilidad y la subjetividad de la fuente. Por el contrario, en la perspectiva posmoderna, la evidencia lejos de ser una ventana se convierte en una suerte de obstáculo que impide el acceso a la realidad. Ginzburg encuentra en esta situación una sucesión de entrampamientos. Para este autor, tanto el positivismo con su ingenuidad teórica, como algunas críticas anti-positivistas (él las llama de un positivismo invertido) que apelan a teorías sofisticadas, comparten un supuesto esquemático e infructuoso: "simplifican la relación entre la evidencia y la realidad". 38

\footnotetext{
${ }^{36}$ Tulio Halperin Donghi, “Campesinado y Nación”, Historia Mexicana XLVI, no. 3 (1996): 522-523.

${ }^{37}$ Ibídem

${ }^{38}$ Carlo Ginzburg, "Checking the Evidence: The Judge and the Historian", en James Chandler, Arnold Davidson y Harry Harootunian, eds., Questions of Evidence. Proof, Practice, and Persuasion across the Disciplines (Chicago: University of Chicago Press, 1994), 294.
} 
La historiografía como un modo discursivo de representación de lo real enfrenta esta compleja relación de diferentes modos. Personalmente creo que la manera más satisfactoria, para decirlo de forma breve y simple, de configurar esa relación es la de postular la evidencia como una huella de lo real. Como dice Paul Ricoeur, "en tanto que la huella es dejada por el pasado, está en su lugar, lo representa" ${ }^{39}$ Inspirándome en la reflexión sobre la relación entre fotografía y realidad que emprende Philippe Dubois ${ }^{40}$ y en el magistral ensayo de Ranahid Guha ("La prosa de contrinsurgencia") ${ }^{41}$ creo que la comprensión de la evidencia como huella de lo real (realidad pasada) nos permite, simultáneamente, evadir la trampa de mirar la evidencia como un reflejo de la realidad, ilusionismo mimético del positivismo, y nos devuelve a la experiencia referencial de constitución de la evidencia, en un momento y lugar (contexto) determinado, restituyendo de esta manera la 'otredad' del pasado. De lo que se trata, entonces, es de indagar de qué la evidencia es huella. Esta perspectiva también nos previene de la tentación de mirar la evidencia como creación cultural arbitraria, de acuerdo a la perspectiva estructuralista

Como nos recuerda Halperín Dongui, la evidencia devuelve la mirada al historiador de maneras imprevistas. Cuando ventriloquizamos a la evidencia, en realidad podemos caer víctimas de nuestras propias ilusiones. En vista de que "el historiador se encuentra constreñido por lo que alguna vez fue" ${ }^{42}$, entonces el estudio de qué es huella la evidencia se torna fundamental. Volviendo al tema de Xochiapulco, en un nivel importa saber de qué son huella los huesos que aparecieron enterrados en la plaza de este pueblo; en otro nivel interesa saber de qué es huella la afirmación de Rivera respecto a que dicha osamenta tuvo nacionalidad austriaca y francesa; y, finalmente, de qué es huella la aseveración de Mallon respecto a que dichos huesos no son europeos sino mexicanos.

Me parece que el enfoque subalterno puede resultar de gran provecho para interpretar las huellas del pasado, a condición de que tomemos en serio la advertencia que preconiza Gyan Prakash $^{43}$. El señala que la comprensión de los estudios subalternos no puede verse limitada al espacio surasiático, que inicialmente fue objeto de su atención, ni tampoco puede ser globalizada sin más. Prakash, advierte, y aquí suscribo su cautela, que tenemos el imperativo de que su traducción ocurra entre líneas.

\footnotetext{
${ }^{39}$ Paul Ricoeur, "La realidad del pasado histórico”, Historia y Grafía, no. 4 (1995): 184.

${ }^{40}$ Philippe Dubois, El acto fotográfico (Barcelona: Paidos, 1994).

${ }^{41}$ Reproducido en Debates poscoloniales.

${ }^{42}$ Ricoeur, "La realidad", 184.

${ }^{43}$ Prakash, "Subaltern Studies", 1490.
} 


\section{Bibliografía}

Adelman, Jeremy. "Spanish-American Leviatán: State Formation in Nineteenth-Century Spanish America. A Review Article", Comparative Studies in Society and History 40, no. 2 (1998).

Amin, Shahid. Event, Metaphor, Memory. Chauri Chaura, 1922-1992. California-Oxford: University of California Press, 1995.

Anrup, Roland y Carlos Vidales. "El padre, la espada y el poder: La imagen de Bolívar en la historia y en la política". En Simón Bolívar 1783-1983: Imagen y presencia del libertador en estudios y documentos suecos. Estocolmo: Instituto de Estudios Latinoamericanos, 1983.

Assadourian, Carlos Sempat. El Sistema de la Economía Colonial. Lima: Instituto de Estudios Peruanos, 1982.

Assadourian, Carlos Sempat et. al. Modos de Producción en América Latina. Buenos Aires: Cuadernos de Pasado y Presente, 1973.

Ayala Mora, Enrique. "Tendencias del desarrollo del culto a Bolívar en el Ecuador". Ponencia presentada al IV Encuentro de ADHILAC, Bayamo, Cuba, julio de 1983.

Beverley, John. "Negotiating with the Disciplines. A Conversation on Latin American Subaltern Studies, with James Sanders", Journal of Latin American Cultural Studies 6, no. 2 (1997).

Subalternity and Representation. Arguments in Cultural Theory. Durhan: Duke University Press, 1999.

Beverley, J., J. Oviedo y M. Ahorna (eds.). The Postmodernism Debate in Latin America. Durham: Duke University Press, 1995. Traducción española de Juan Zevallos Aguilar publicada en Procesos, revista ecuatoriana de historia, no. 10 (1997).

Chakrabarty, Dipesh. "Subaltern Studies and Postcolonial Historiography". Nepantla: Views from South 1, no. 1 (2000).

Chiaramonti, José Carlos. Ciudades, provincias, estado. Orígenes de la Nación Argentina. Buenos Aires: Ariel, 1997.

Colmenares, Germán. Sociedad y Economía en el Valle del Cauca. Cali: Universidad del Valle, 1983.

Coronil, Fernando. "Listening to the Subaltern: the Poetics of Neocolonial States", Poetics Today 15, no. 4 (1994).

. The Magical State. Chicago: University of Chicago Press, 1997.

Duara, Prasenjit. "Historicizing National Identity, or Who Imagines What and When". En Becoming National. A Reader, Geoff Eley y Ronald Grigor Suny, eds. Oxford: Oxford University Press, 1996.

Dube, Saurabh coord. Pasados Poscoloniales. México: El Colegio de México, 1999.

Dubois, Philippe. El acto fotográfico. Barcelona: Paidos, 1994. 
Espinosa, Carlos. "La mascarada del Inca: una investigación sobre el teatro político en la colonia". En Miscelánea Histórica Ecuatoriana, II. Quito: Museos del Banco Central, 1989.

. "El retorno del Inca: Los movimientos neoincas en el contexto de la intercultura barroca", Procesos, revista ecuatoriana de historia, no. 18 (2002).

Flores Galindo, Alberto. Aristocracia y Plebe. Lima, 1760-1830. Lima: Mosca Azul Editores, 1984.

. Buscando un Inca. Lima: Editorial Horizonte, 1987.

Ginzburg, Carlo. "Checking the Evidence: The Judge and the Historian". En Questions of Evidence. Proof, Practice, and Persuasion across the Disciplines, James Chandler, Arnold Davidson y Harry Harootunian, eds. Chicago: University of Chicago Press, 1994.

Halperin Donghi, Tulio. “Campesinado y Nación”, Historia Mexicana XLVI, no. 3 (1996).

Larson, Brooke. "Shifting Views of Colonialism and Resistanse", Radical History Review, no. 27 (1983).

. Colonialismo y Transformación Agraria en Bolivia. Cochabamba, 1500-1900. La Paz: CERES - HISBOL, 1992.

MacCormack, Sabine. “'En los tiempos muy antiguos...' Cómo se recordaba el pasado en el Perú de la colonia temprana”, Procesos. Revista ecuatoriana de historia, no. 7 (1995).

Mallon, Florencia. "The Promise and Dilemma of Subaltern Studies: Persectives from Latin American History", American Historical Review 99, no. 5 (1994).

Peasant and Nation. The making of poscolonial Mexico and Peru. Berkeley: University of California Press, 1995.

Murra, John. Formaciones económicas y políticas del mundo andino. Lima: IEP, 1975.

Prakash, Gyan. "Subaltern Studies as Postcolonial Criticism", American Historical Review 99, no. 5 (1994).

Rappaport, Joanne. Cumbe Reborn. An Andean Ethnography of History. Chicago: Chicago University Press, 1994.

Ricoeur, Paul. "La realidad del pasado histórico", Historia y Grafia, no. 4 (1995).

Rivera Cusicanqui, Silvia. "Oprimidos pero no Vencidos". Luchas del campesinado aymara y qhechwa de Bolivia, 1900-1980. La Paz: Hisbol - Esutcb, 1984.

Rivera Cusicanqui, Silvia y Rossana Barragán comp. Debates poscoloniales. Una introducción a los estudios de la subalterninadad. La Paz: Historias - Sephis, 1997.

Spalding, Karen. De indio a campesino. Lima: IEP, 1974.

Stern, Steve. Los pueblos indígenas del Perú y el desafio de la conquista española. Madrid: Alianza Editorial, 1986.

"Feudalism, Capitalism, and the World-System in the Perspective of Latin America and the Caribbean", American Historical Review 93, no. 4 (1988).

Thurner, Marc. From Two Republics to One Divided. Durham: Duke University Press, 1997.

Trouillot, Michel-Rolph. Silencing the Past. Power and the Production of History. Boston: Beacon Press, 1995. 